throughout the mask and the inspired $\mathrm{CO}_{2}$ at all flows was virtually zero.

A Venturi can be made to give an adjustable oxygen concentration by throttling the air intake. This is rather too heavy a device to be incorporated in a mask, but can be connected to it. It also seems to work well in a small tent covering the head and shoulders and can also be used to control oxygen concentration in a standard oxygen tent. We do not yet know whether to recommend the production of a range of singleconcentration masks or to use some other device to provide a range of concentrations. I suspect that the mask now available giving $27 \%$ oxygen will cover most requirements, but that another one giving a concentration of $24 \%$ will also have to be available; if so, it can be made. I now doubt if great precision will be required at higher levels. The problem is not technical or physiological but clinical: we need to know more about the response of patients.

Users of the existing Venturi mask should realize that, although it is not as good as the prototype, it is still better than other commercially available masks from the standpoints of oxygen concentration and $\mathrm{CO}_{2}$ washout. I have, however, been at fault in not recommending Messrs. Oxygenaire to modify the claims made for its accuracy.

Finally, I must stress that these technical shortcomings should not obscure the facts that oxygen therapy must be continuous. not intermittent ; that the oxygen concentration must be controlled, and that the easiest way of achieving this is to use the principle of high air-flow with oxygen enrichment.-I am, etc.,

MORAN CAMPBELL.

Postgraduate Medical School,

London W.12.

REFERENCE

1 Campbell, E. J. M., Lancet, 1960, 2, 12.

\section{Cystic Myxomatous Degeneration of Popliteal Artery}

SIR,--In their interesting article on this unusual cond tion (October 5, p. 847) $\mathrm{Mr}$ B. P. Bliss, Dr. J. Rhodes, and Professor A. J. Harding Rains raise two questions concerning its diagnosis from Buerger's disease, and its late prognosis, which can be partly answered from the findings in an unreported case of mine diagnosed clinically and operated upon a little over three years ago.

The cause of calf claudication in a young subject should be considered to be cystic degeneration if, as happened in this case, an arterial murmur can be heard on auscultation over the popliteal fossa and the patient is a non-smoker. These two findings are strong evidence against the diagnosis of Buerger's disease, which is almost unknown in non-smokers and which produces thrombotic occlusion of the distal arteries and not narrowing, as in atheroma or cystic degeneration.

The prognosis with operation should be good, for, as Mr. Bliss and his colleagues

point out, cystic arterial disease appears to be localized and unrelated to the more serious form which occurs in the thoracic aorta leading to dissecting aneurysm. Grafting the popliteal artery has not proved successful in long-term analysis, but local operations conserving the artery may be better, as Cockett and Maurice have found.' Evacuation of the cysts and simple suture-reconstruction of the popliteal artery should be effective unless aneurysmal dilatation should develop.

Mr. Bliss and his colleagues wished for information on cases operated upon several years ago: at three years my patient's condition remains satisfactory and he has full use of this limb despite a fractured tibia in the meantime.- 1 am, etc.,

London W.1. H. H. G. EASTCOTT.
REFEREnce
Cockett, F, B. and Maurice, B. A., Brit, med J., $1963,1,353$.

\section{Surgery of Peptic Ulcer}

SIR, - I beg the courtesy of your columns to correct certain inaccuracies in reporting the views which I expressed (or believed I had expressed) in the course of the Panel Discussion on "Surgery of Peptic Ulcer" during the B.M.A. Annual Clinical Meeting at Stoke on October 20 (B.M.J., November 2, p. 1116).

Firstly, I am prepared to consider the use of vagotomy with pyloroplasty as treatment for carefully selected patients with perforated duodenal ulcer-not, as inferred, for perforated gastric ulcer. Secondly, the only acceptable method of testing for completeness of vagal nerve section at the time of operation is that described and used routinely by $\mathrm{Mr}$. Harold Burge. No more reliable method has been proposed for use in patients, and Burge's technique merits further evaluation. Thirdly, in reply to Mr. R. V. Cooke, who asked the Panel what should be done for the patient with haematemesis if nothing was found at laparotomy, I emphasized the need for wide gastrotomy and pyloro-duodenotomy. If nothing is found after the meticulous inspection of the gastro-duodenal mucosa afforded by this procedure. I would do nothing more - not. as reported. a pyloroplasty with vagotomy. Finally, while "sprouting " from the central cut end of the vagus has been beautifully demonstrated by Mr. Greig Murray and his colleagues. I am not aware that "regrowth" has been demonstrated (in the sense of restoration of vagal continuity, both anatomically and functionally).-I am, etc.

$$
\begin{aligned}
& \text { Royal Infirmary, } \\
& \text { Sheffield 6. }
\end{aligned}
$$

\section{Anticonvulsants}

SIR,-I have a few comments to make about the most excellent article on anticonvulsants which you published under "Current Practice" on October 12 (p. 919).
Firstly, with regard to phenytoin you imply that it is difficult to obtain a parenteral preparation of phenytoin. Parke-Davis make a preparation, "epanutin parenteral," and this can be extremely useful in the treatment of status epilepticus in adults as well as in children. Hypertrophy of the gums occasionally can be a serious complication of phenytoin therapy in that it can become so gross that the drug has to be stopped.

Secondly, with regard to ethosuximide, skin rashes have been reported with this drug. I have seen a case personally, and the fact is stated in the manufacturers' literature, where they quote personal communications to the company and also by Lossius. ${ }^{1}$ - I am, etc.,

Charles A. Simpson.

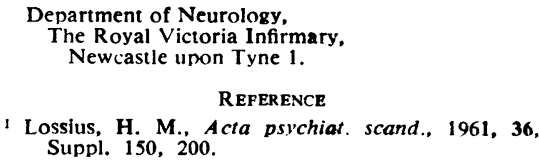

\section{Diagnosis of Coarctation}

SiR,-Dr. R. A. Strang's letter (November 2 , p. 1129) has drawn attention to a necessary part of the examination of a child-feeling the femoral pulses. This is important in the diagnosis of coarctation, but may I suggest that the brachial pulse be palpated at the same time. About $25 \%$ of such cases do have femoral pulses, ${ }^{1}$ but there is a significant delay in the latter which can only be appreciated by practice.-I am, etc.,

\section{Farnborough Hospital,
Farnborough, Kent.}

P. RoBSON.

\section{REFERENC}

1 Keith. J. D., Rowe. R. D., and Vlad. P., Heart Disease in Infancy and Childhood, 1958 p. 174. Macmillan, New York.

\section{Cystic Fibrosis Group}

SiR,-The Cystic Fibrosis Group was formed in October, 1960. mainly as a friendly link between parents of children with fibrocystic disease of the pancreas. We feel that the time has come to expand the group. Until now we have been mainly a social group, waiting for people to contact us. Now we feel that we can extend our work, and would welcome other parents who would like to join our group. We have a quarterly newsletter giving general news and having articles of interest for the parents.

The group is a happy association of parents and certainly not a "grumble group." It is characterized by a positive approach to the problems that we all share. We would be most grateful if your readers would tell any parents that thev think would be interested in our group of our work. We would be pleased to welcome them into the group and send them newsletters. We have a limited number of past newsletters available on loan.-I am, etc.,

The Cystic Fibrosis Group, JUNe MEAD.

Hawkridge Road. 